\title{
Conjugate Heat Transfer Study of Combined Impingement and Showerhead Film Cooling Near NGV Leading Edge
}

\author{
Dileep Chandran and Bhamidi Prasad \\ Thermal Turbomachines Laboratory, Department of Mechanical Engineering, Indian Institute of Technology Madras, \\ Chennai 600036, India \\ Correspondence should be addressed to Bhamidi Prasad; prasad@iitm.ac.in
}

Received 30 May 2014; Revised 20 September 2014; Accepted 4 October 2014

Academic Editor: Giovanni Carlomagno

Copyright (C) 2015 D. Chandran and B. Prasad. This is an open access article distributed under the Creative Commons Attribution License, which permits unrestricted use, distribution, and reproduction in any medium, provided the original work is properly cited.

\begin{abstract}
A computational and experimental study is carried out on the leading edge region of a typical gas turbine NGV, cooled by a combination of impingement and showerhead film cooling. A detailed flow and conjugate heat transfer study has revealed the complex flow structure owing to the coolant-mainstream interaction and the influence of vane material thermal conductivity. The local effectiveness values obtained by the computations agreed well with the experimental data from IR thermography. The effect of blowing ratio on the overall effectiveness is found to be strongly dependent on the vane material conductivity. The effect of blowing ratio is also found to be different towards the pressure and suction sides of the stagnation region. However, the overall effectiveness is found to decrease by about $12 \%$ and $6 \%$ for low and high conducting materials, respectively, with an increase in mainstream Reynolds number from $\mathrm{Re}=4.8 \times 10^{5}$ to $14.4 \times 10^{5}$.
\end{abstract}

\section{Introduction}

Heat transfer studies related to the leading edge cooling of a nozzle guide vane $(\mathrm{NGV})$ are of great relevance and interest for the design of modern gas turbines, as it is the part mostly exposed to the hot gases. An improper understanding and design of cooling configuration in this region may cause very high thermal stress and may ultimately lead to the failure of the blade. Hence the effects of film hole configuration, blowing ratio, coolant to mainstream density ratio, Reynolds number, and mainstream turbulence intensity on heat transfer near the leading edge have been of immense interest to researchers.

Most of the earlier investigations were reported by comparing the adiabatic effectiveness $(\eta)$ on the leading edge surface, which is defined as follows:

$$
\eta=\frac{T_{m}-T_{\mathrm{aw}}}{T_{m}-T_{c}} .
$$

Here, $T_{m}, T_{c}$, and $T_{\text {aw }}$ are the mainstream, coolant, and the adiabatic wall temperatures, respectively. Mehendale and JeChin [1] used a cylindrical model with two rows of film holes for studying the effect of Reynolds number and film hole spacing on the adiabatic effectiveness. They found an increase in effectiveness value with increase in Reynolds number. A similar study was conducted by $\mathrm{Ou}$ and Rivir $[2,3]$ by adding an extra row of film holes at the stagnation region and concluded that the Reynolds number effect is significant at low blowing ratios and high turbulence. The effect of mainstream turbulence was also investigated by Funazaki et al. [4] for cylindrical as well as diffuser holes. They reported a reduction in spanwise effectiveness with increase in turbulence for both holes. Similar investigations were conducted to find the effect of different hole shapes $[5,6]$, inclinations, and injection angles [7] on the adiabatic effectiveness distribution.

The emphasis on the conjugate heat transfer (CHT) technique is reported in recent studies where a wide variation was found in the temperature distribution over a vane under adiabatic and conjugate conditions $[8,9]$. Montomoli et al. [10] carried out CHT calculations on a cylindrical leading edge and prescribed the use of high conductivity material for turbine nozzles. Their model contained two rows of film holes on either side of the stagnation region and a row of impingement holes inside. Moritz et al. [11] used a CHT 


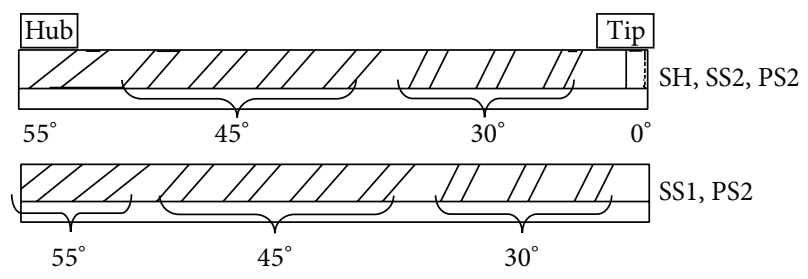

(a)

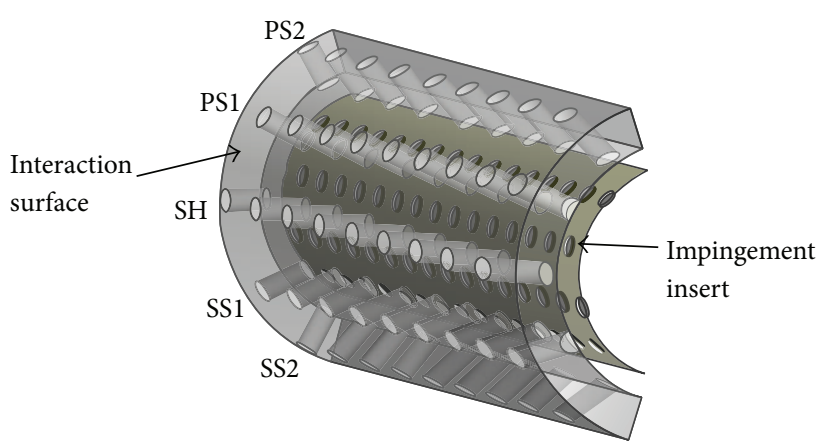

(b)

FIgURE 1: (a) Inclination of holes within a row from hub to tip. (b) Solid leading edge with impingement insert.

code developed at their institute and demonstrated that a conjugate calculation technique is suited for predicting threedimensional thermal load on blades with complex cooling configurations. A key parameter used in CHT calculations is the overall cooling effectiveness $(\Phi)$. This variable gives an idea of the actual vane temperature in the nondimensional form by coupling the convective heat transfers due to the external and internal flow field with the conduction in the blade:

$$
\Phi=\frac{T_{m}-T_{w}}{T_{m}-T_{c}}
$$

Here $T_{w}$ is the wall temperature under conjugate condition. The values of adiabatic and overall cooling effectiveness at the leading edge region of a turbine vane with internal impingement cooling were compared by Nathan et al. [12]. They reported that the values of $\Phi$ are equivalent to the actual engine values and are higher compared to the adiabatic effectiveness. They prescribed the use of contours of $\Phi$ for determining the regions of high thermal gradient.

Even though there are a lot of studies related to leading edge heat transfer, data on parametric studies carried out with conjugate thermal conditions with realistic external and internal cooling configurations are limited. Literature does not throw much light on the effect of some of the key parameters like blowing ratio, Reynolds number, and material conductivity on the overall effectiveness of the leading edge with the conjugate conditions. The present study hence focuses on these aspects by considering a NGV cascade with the leading edge of a typical gas turbine provided with showerhead holes and impingement holes. The parameters investigated in the study include the effect of three different blowing ratios and the effect of three different Reynolds numbers for each blowing ratio on the overall effectiveness of the leading edge made of different thermal conducting materials.

\section{Methodology}

2.1. Computational Methodology. Studies are conducted on a curved plate having a radius of curvature $21 \mathrm{~mm}$ and thickness $5 \mathrm{~mm}$, provided with five rows of $2.85 \mathrm{~mm}$ diameter staggered showerhead holes. The middle row of holes $(\mathrm{SH})$ is at the stagnation region and the other four rows, SS1, SS2, PS1, and PS2, are positioned at $+30^{\circ},+60^{\circ},-30^{\circ}$, and $-60^{\circ}$, respectively, from the middle row. Typical to a gas turbine NGV, these holes in each row are varyingly inclined in the spanwise direction from $55^{\circ}$ to $0^{\circ}$ as shown in Figure 1(a).

The computational domain is a linear cascade as shown in Figure 2(a). The chord length of the blade is $228 \mathrm{~mm}$ and the spacing between the blades is maintained at $200 \mathrm{~mm}$. The NGV has a span of $100 \mathrm{~mm}$. To avoid end wall effects, the NGV is extended on either side by $100 \mathrm{~mm}$ resulting in a total span of $300 \mathrm{~mm}$. The domain is extended 1.5 times the chord upstream and downstream of the blades.

The computational model consists of two fluid zones and a solid zone. Fluid zone 1 is the mainstream flow and fluid zone 2 is the coolant flow from the impingement holes to the vane rear surface and through the film holes to finally mix with fluid zone 1 . The solid zone comprises the leading edge region. The mesh is generated in these zones by the grid generating tool GAMBIT 2.3.16 (Figure 2(b)). A grid independence study is conducted with three meshes, coarse, medium, and fine, which had approximately 1.7 million, 2.54 million, and 3.1 million cells, respectively. The spanwise averaged effectiveness at various streamwise locations is plotted for all three cases as shown in Figure 3.

The medium mesh is found adequate for the present study as the result was almost independent of further grid refinement. A multiblock technique is used and it allows creating separate grids for different parts of the flow domain. The interblock boundaries are virtual and hence have no physical significance. The impingement holes, film holes, and the solid leading edge are meshed with tetrahedral grid and are well refined. On the other hand, the flow domain is meshed with hexahedral grids. A three-dimensional boundary layer with first row height of $0.02 \mathrm{~mm}$ and growth factor of 1.2 for 20 rows is provided throughout over the blade surface and over the film hole exits to bring down the $y+$ value of the 1st cell below unity.

At the cascade domain inlet and impingement hole inlet, a uniform velocity and temperature boundary condition is specified for the mainstream flow and coolant flow, respectively. The coolant from the inlet impinges on the rear side of the leading edge and then effuses out of the film (showerhead) holes to interact with the mainstream and finally exits 


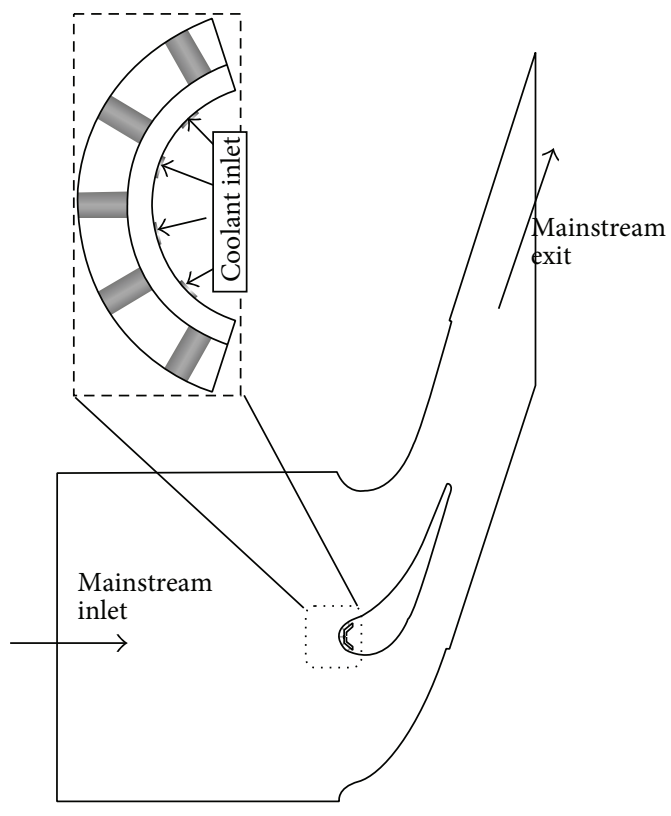

(a)

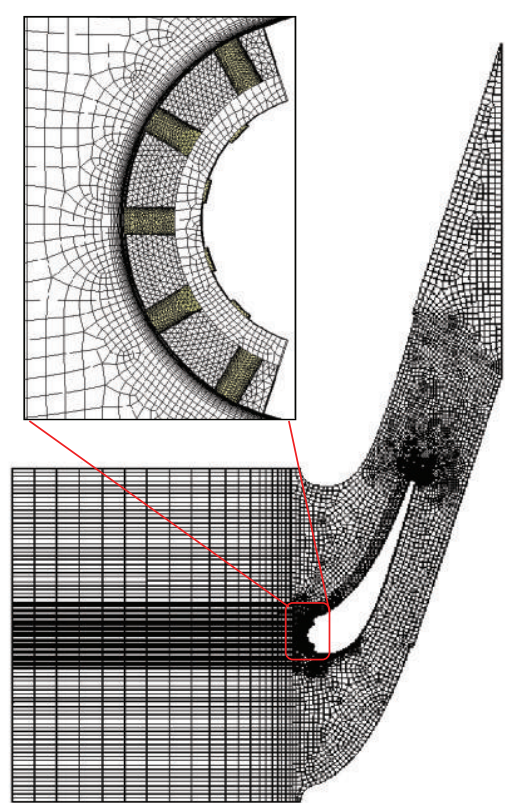

(b)

Figure 2: (a) Computational domain. (b) Mesh generated in the domain.

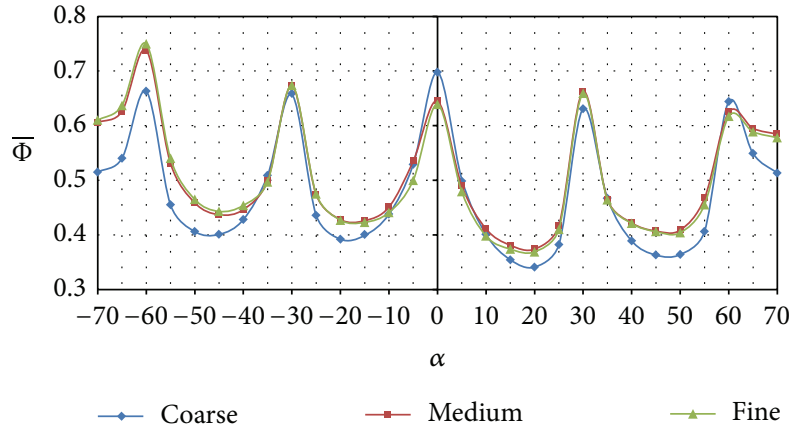

FIGURE 3: Grid independence study.

the domain through a constant pressure outlet. A turbulent intensity of $1 \%$ is imposed at the mainstream inlet and $5 \%$ at the impingement inlet. A periodic boundary condition is given at the top and bottom wall of the domain so as to generate an infinite cascade model.

Three-dimensional conjugate heat transfer problem is formulated with the following assumptions: (i) the fluid is incompressible, (ii) the fluid properties are constant, (iii) radiation and natural convection are neglected, (iv) viscous dissipation is absent, and (v) the flow is steady. The governing equations used for simulation are the Reynolds averaged continuity, momentum, and the energy equations along with the equations for modeling the turbulence quantities.

Boundary conditions used for the present study are as follows:

(i) no slip boundary condition at wall, $v_{w}=0$;

(ii) mainstream velocity inlet $\left(v_{m}\right)$ corresponding to different Reynolds numbers and $T=308 \mathrm{~K}$; (iii) coolant inlet condition, $T=288 \mathrm{~K}$, and $v_{c}$ calculated from blowing ratio $\left(M=\rho_{c} v_{c} / \rho_{m} v_{m}\right)$;

(iv) outlet boundary condition, $P=P_{\mathrm{amb}}$ at exit;

(v) conjugate boundary condition at solid plate,

$$
T_{s}=T_{f}, \quad k_{s} \frac{\partial T_{s}}{\partial y}=k_{f} \frac{\partial T_{f}}{\partial y} \quad \text { at wall; }
$$

(vi) adiabatic condition at the other walls,

$$
\frac{\partial T_{s}}{\partial y}=0 \quad \text { at wall. }
$$

The governing equations are solved using the finite volume based Fluent14 solver from the Ansys14 package. The $\kappa-\omega$ SST model is adopted for turbulence modeling. This model was recommended by Panda and Prasad [13], who conducted a combined impingement-film cooling study on a flat plate, where the $\kappa-\omega$ SST model is reported to have predicted the flow interactions very well and matched with their experimental results. A standard pressure interpolation scheme is used. The SIMPLE algorithm is used for pressurevelocity coupling. A second-order upwind scheme is used for momentum and energy and a first-order upwind scheme for $\kappa$ and $\omega$. The solution is considered to be converged when the maximum residual value is of the order of $10^{-5}$ for continuity, momentum, and turbulence equations and $10^{-6}$ for the energy equation. Further, the spanwise averaged effectiveness values at various streamwise locations on the $\mathrm{NGV}$ are constantly monitored so that the variation will be within $0.1 \%$ for 500 consecutive iterations.

For the present study, two curved plates, one with a lower thermal conductivity (Material A with $k=0.2 \mathrm{~W} / \mathrm{mK}$ ) and 


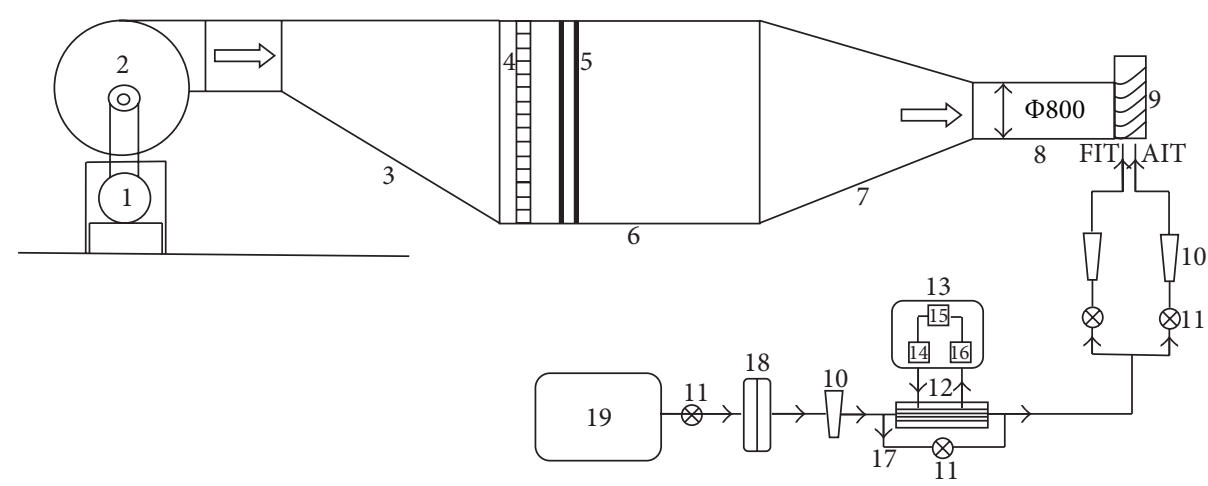

FIGURE 4: Experimental test rig. 1: DC motor $75 \mathrm{~kW} 1500 \mathrm{rpm}, 2$ : centrifugal air blower $14 \mathrm{~m}^{3}$ /s, 3: diffuser, 4: honeycomb, 5: mesh, 6: settling chamber, 7: converging duct, 8: test section, 9: cascade, 10: rotameter, 11: flow control valve, 12: heat exchanger, 13: condensing unit, 14: thermostatic expansion valve, 15: condenser, 16: refrigerant compressor, 17: bypass, 18: air dryer, and 19: reciprocating air compressor.

another with a higher thermal conductivity (Material B with $k=14.9 \mathrm{~W} / \mathrm{mK}$ ), are considered. The effect of blowing ratio is studied at $M=1,1.5$, and 2 by varying the coolant velocity maintaining the mainstream velocity constant. The effect of Reynolds number is studied at each blowing ratio by varying both mainstream and coolant velocity. Reynolds number is varied by $\mathrm{Re}_{1}=4.8 \times 10^{5}, \mathrm{Re}_{2}=9.6 \times 10^{5}$, and $\mathrm{Re}_{3}=14.4 \times$ $10^{5}$ for each blowing ratio and its effect on the overall effectiveness on the leading edge external surface is studied.

2.2. Experimental Methodology. The computational model is validated with the experimental results obtained from the study carried out on a five-vane cascade in the laboratory linear cascade wind tunnel. The center vane in the cascade is instrumented for static pressure and temperature measurements. The cascade and vane dimensions are exactly the same as those of the computational model. The experimental setup is shown in Figure 4. The mainstream air is supplied by a centrifugal blower. A uniform flow is ensured by the honeycomb screens and meshes provided in the settling chamber as shown in the figure. The secondary air is supplied by a reciprocating air compressor and is cooled using a tube-in-tube heat exchanger. The coolant is fed into the two impingement inserts fitted inside the NGV. The coolant impinges on the rear side of the vane and effuses out of the showerhead and film holes.

The two-dimensionality and periodicity of the cascade are established using flow measurements at the inlet and exit of the cascade. A pitot probe is traversed at the inlet of the cascade and a calibrated five-hole pressure probe at the exit. The static pressure on the vane is measured using static taps put at various streamwise locations. The air is bled from these static taps using $2.5 \mathrm{~mm}$ brass tubes.

The steady state temperature on the external surface of the NGV made of Material B is measured by infrared thermography using a FLIR A315 camera. The entire leading edge is mapped by placing the camera at three different locations (as shown in Figure 5(b)) so as to bring down the maximum viewing angle, between the camera and the normal surface, below $35^{\circ}$. This is done to avoid any variance in directional emissivity, as previous study [14] has reported that the emissivity is nearly constant from the normal direction $\left(0^{\circ}\right)$ to $45^{\circ}$. Germanium IR windows are placed on the tunnel walls at all these locations. The camera is connected to the computer using a gigabit Ethernet cable and the FLIR Tools+ software enable triggering, synchronization, and focus of the camera remotely. Various corrections like atmosphere transmission correction, emissivity correction, reflected temperature correction, external windows correction, and optics transmission correction are made before taking the image. In situ calibration of the IR camera is done by simultaneously recording the temperatures obtained from calibrated thermocouples that are stuck at various locations on the NGV. The NGV along with the thermocouples are painted with flat black to achieve uniform emissivity of about 0.97. The emissivity is then corrected by comparing the IR and thermocouple readings, even though the magnitude of this correction is as low as 0.01 . Lines of equal length are drawn at various streamwise locations on the vane surface. The weighted averages of temperature in all these lines are obtained.

\section{Data Reduction Planes}

The lines drawn on the leading edge as in Figure 6 from $\alpha=-70$ to +70 at every 5 -degree interval are used for data reduction. The spanwise averaged effectiveness discussed in the later sections is obtained by area weighted average of these lines. Wall-normal planes from the leading edge surface are also generated with respect to these lines.

\section{Results and Discussion}

4.1. Validation. The computational model is validated by comparing the static pressure and effectiveness distribution on the vane obtained computationally with experiments (Figures 7 and 8). The NGV used in the experiment has the properties of Material $\mathrm{B}$. The static pressure is measured at $\mathrm{Re}=$ $2.9 \times 10^{5}$. For validation, the coolant inlet condition is changed from velocity boundary condition at the impingement hole inlet to mass flow boundary condition at the impingement insert inlet to match the experimental condition. This coolant 


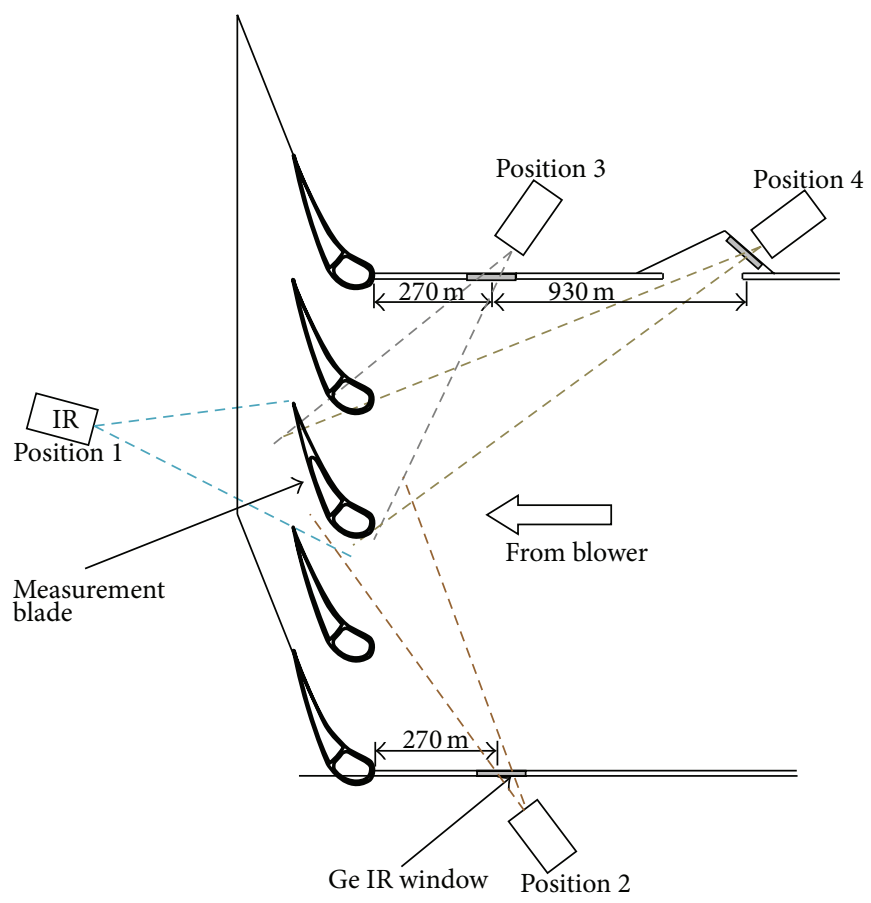

(a)

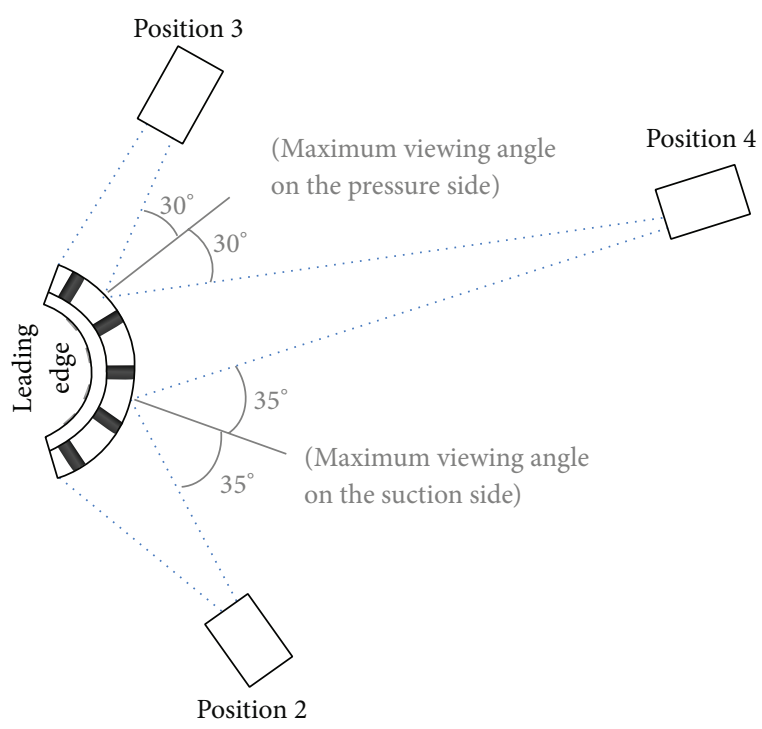

(b)

FIGURE 5: Surface temperature mapping using IR thermography: (a) general cascade setup and (b) focusing the leading edge.
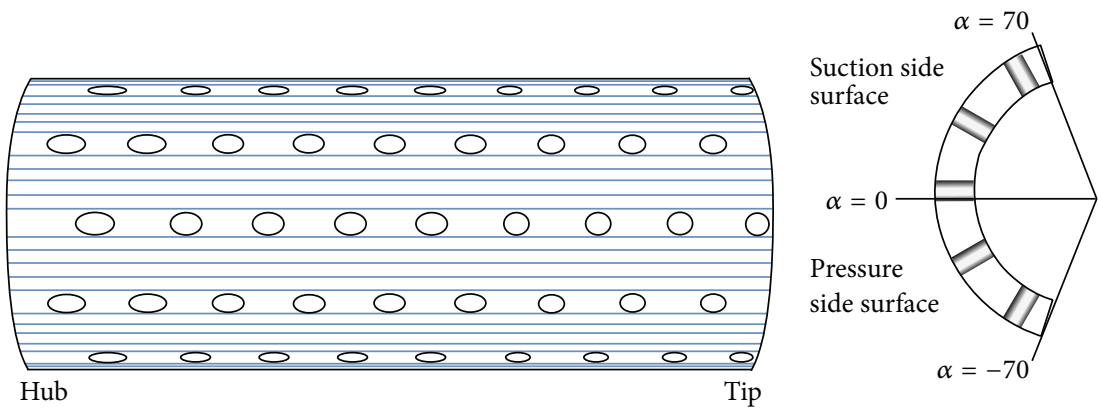

FIGURE 6: Data reduction planes.

mass flow distributed to the showerhead holes as well as four rows of film holes. Hence the minimum blowing ratio $\left(M_{\text {min }}\right)$ corresponds to minimum mass flow rate at the inlet of impingement insert which is sufficient enough for the coolant to come out of all the showerhead and film holes. This value is found out computationally by trial and error. Later, while conducting experiments at this minimum coolant mass flow, it is ensured that the coolant comes out of all the film holes, by traversing a thermocouple probe.

Figures 7 and 8 show that a good correspondence exists between the experimental and computational results, thereby validating the computational methodology, including the mesh and the turbulence model adopted for the computations. Figure 8 shows the IR image at the leading edge and comparison of the experimental and computational values of the spanwise averaged effectiveness. The comparison made for three blowing ratios shows a good agreement between the experimental and computational values with a maximum difference of about $6 \%$, which is well within the acceptable range.

4.2. Flow and Temperature Patterns. The flow and heat transfer characteristics are different on the pressure and suction sides of the leading edge for different blowing ratios. Figure 9 shows the path lines coloured by nondimensional temperature emerging from all rows of holes.

Figure 9 shows the coolant emerging out of the five rows of showerhead holes located at the leading edge. These streamlines are coloured by nondimensional temperature, $\theta$. At low blowing ratio $(M=1)$, the coolant coming out of the stagnation row of showerhead holes is getting equally distributed towards the pressure and suction sides. Symmetry is seen with respect to the stagnation row. But, as the blowing ratio increases, more coolant tends to flow 


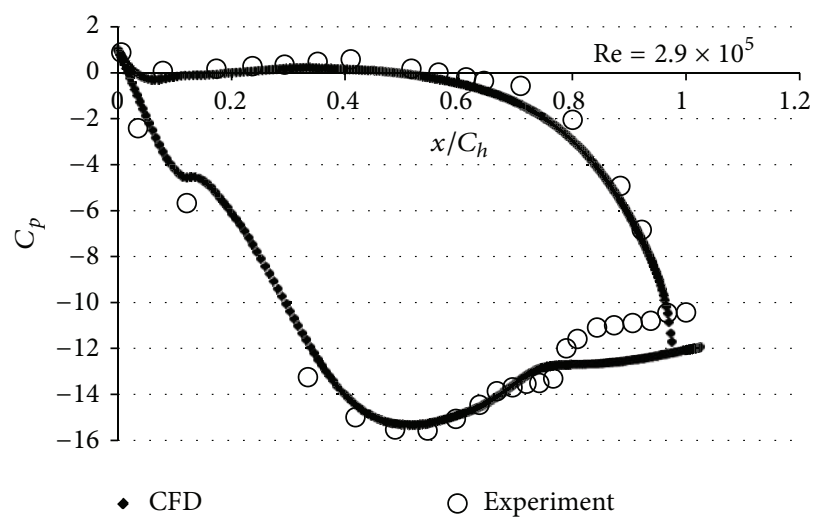

FIGURE 7: Comparison of static pressure.
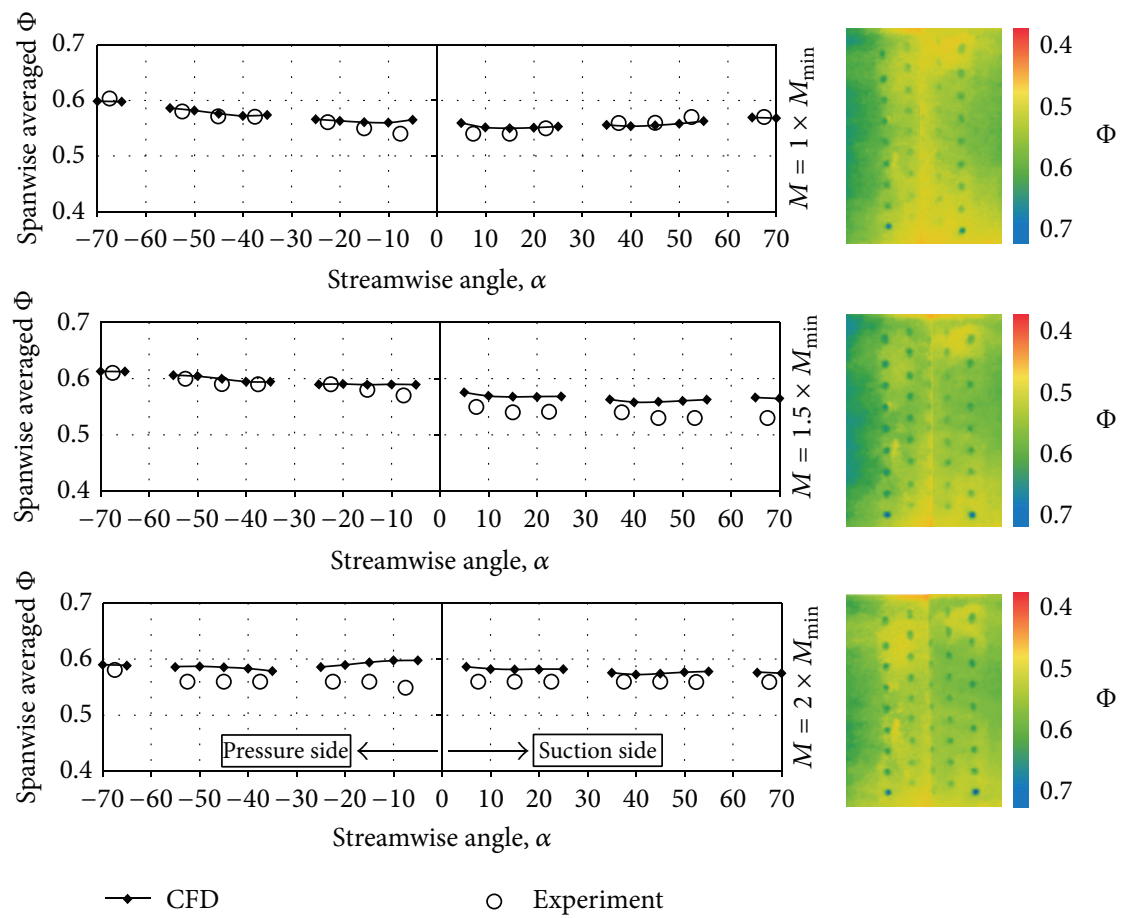

FIGURE 8: Comparison of spanwise averaged overall effectiveness and the IR images.

towards the pressure side compared to the suction side. This is prominent at the highest blowing ratio, $M=2$. The areas not covered by the streamlines are the ones having the lowest effectiveness. Hence pressure side surface has better coolant spread at higher blowing ratios. The reason behind this is explained with the help of Figure 10.

Figure 10 shows the streamlines coloured by nondimensional temperature $(\theta)$ drawn in wall-normal planes L1, L2, and L3 (shown at the top) at different locations along the stagnation row. Planes are drawn just after the first hole, just before the second hole, and through the second hole of the $\mathrm{SH}$ row. It can be seen that, after hole 1 , counter rotating vortex pair (CRVP) is formed for $M=1.5$ and $M=2$. In the case of $M=1$, CRVP are not formed and this is characterized by an attached flow. The strength of the CRVP formed for $M=2$ is higher compared to $M=1.5$. From the second plane which is just before the second hole, it is evident from the colour of the streamlines that the coolant from the 1st hole is not reaching the second hole for $M=1$ case. Hence it is not affecting the coolant flow from the second hole. As a result the coolant streamlines from the 2 nd hole are getting equally distributed to pressure and suction sides as shown in plane L3. But this is not the case for higher blowing ratios where the coolant from the 1st hole is affecting that from the 2 nd hole. At $M=1.5$, even though the coolant from the 1st hole reaches the 2 nd hole, the strength of the CRVP developed from the 1st hole drastically reduces by the time it reaches the 2 nd hole. Though weak, there is a small current towards the pressure side as can be seen from plane L2. Hence, it can be noticed from plane L3 that the coolant is flowing slightly more towards the pressure 

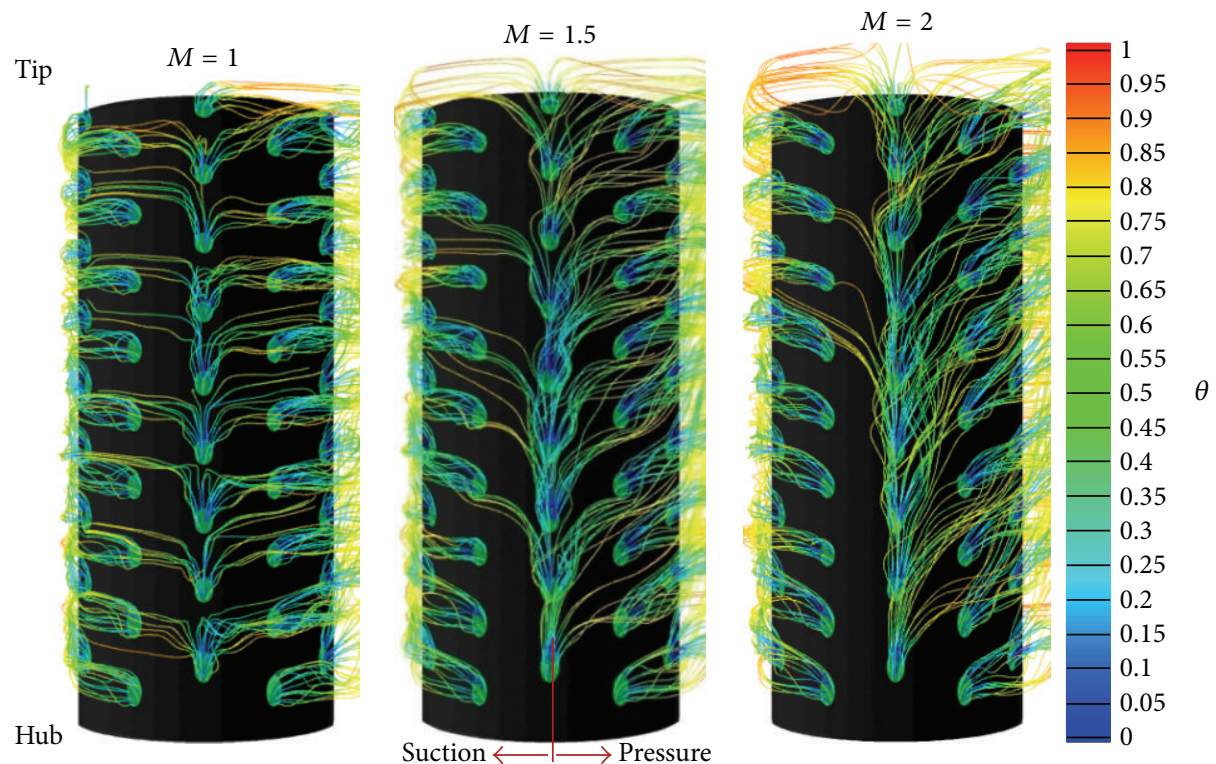

FIGURE 9: Pathlines coloured by nondimensional temperature emerging out of the showerhead holes.
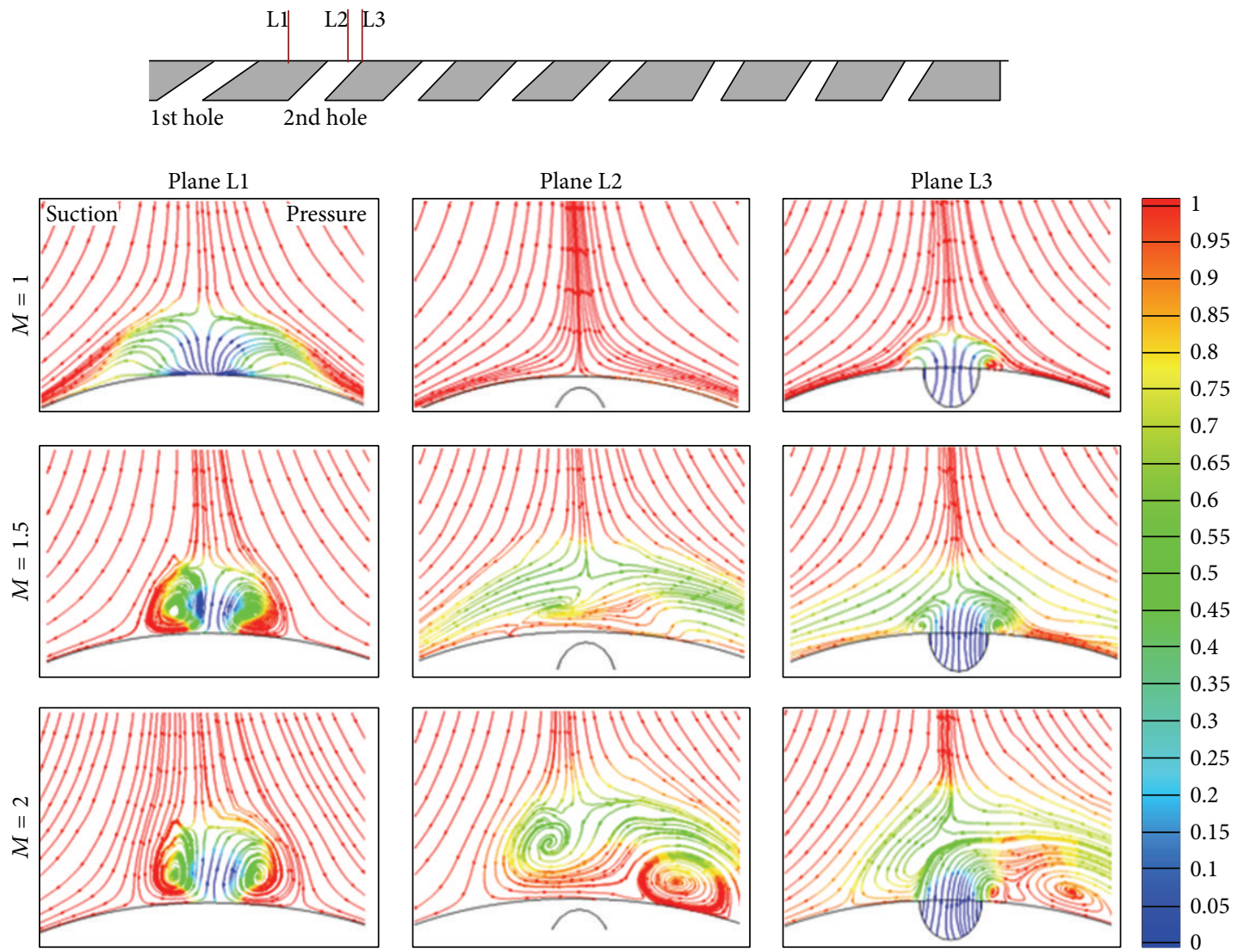

FIGURE 10: Stream lines coloured by $\theta$ drawn at wall-normal planes at various locations in the SH row of the leading edge.

side as compared to suction side. This phenomenon is even more prominent for the highest blowing ratio $(M=2)$. It can be seen from plane L2 that, for the flow approaching hole 2, CRVP has considerable strength. A strong vortex formation is seen on the pressure side and it induces a low pressure in that region. This causes the coolant coming out of the 2 nd hole to flow towards the pressure side as can be seen from plane L3. This is the reason why the coolant effusing out of $\mathrm{SH}$ row is 


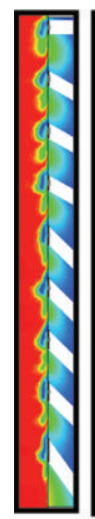

$65^{\circ}$

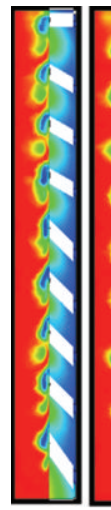

$65^{\circ}$

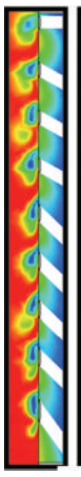

$65^{\circ}$

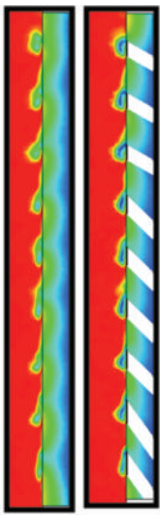

$50^{\circ} \quad 35^{\circ}$

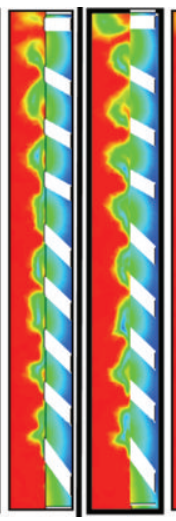

$5^{\circ}$

\begin{abstract}
$-5^{\circ}$
\end{abstract}
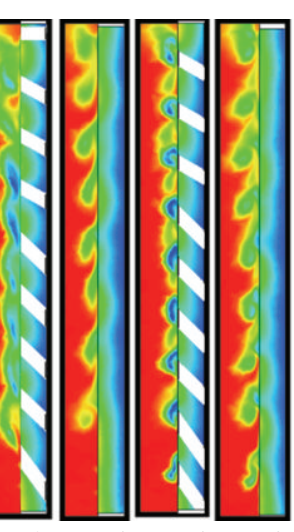

$-35^{\circ}-50^{\circ}$
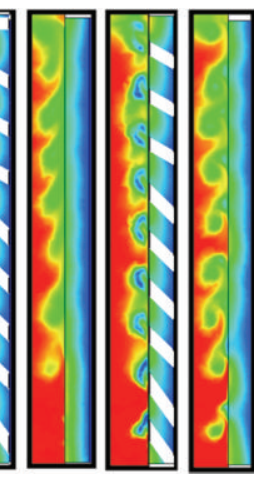

$-20^{\circ}$

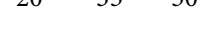

Pressure surface
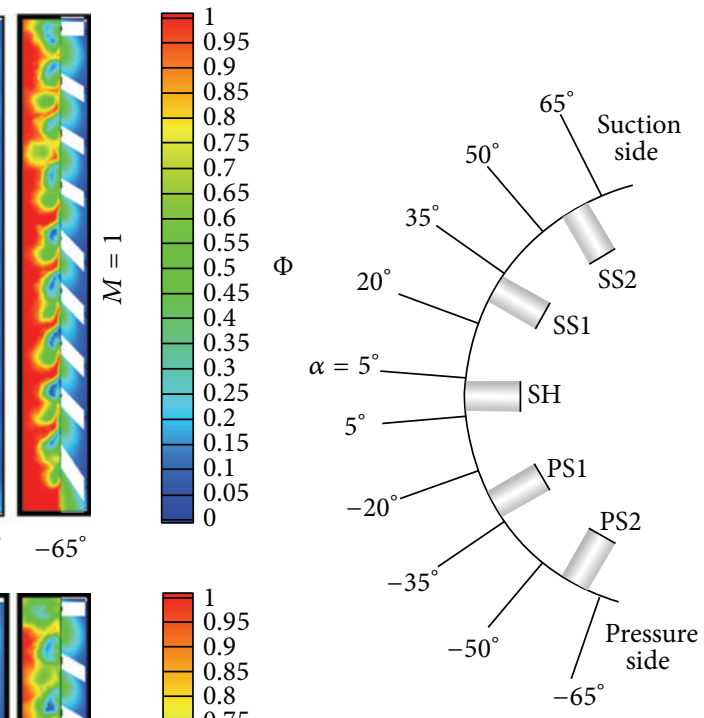

$\Phi$

0.5
-0.45

-0.5
-0.45
0.4

0.4
0.35

0.3
-0.25

0.25
0.2
0.15

0.15
-0.1

0.05

0.05
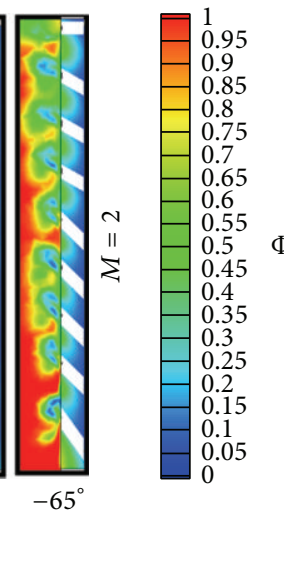

FIGURE 11: Contours of nondimensional temperature $(\theta)$ plotted on wall-normal planes at different streamwise locations for various blowing ratios at $\mathrm{Re}_{1}$.

distributed more towards the pressure side at higher blowing ratios.

Figure 11 shows the nondimensional temperature contour plotted at different wall-normal planes perpendicular to the leading edge (along the data reduction lines, Figure 6). As seen in the figure, the contours at $\pm 5^{\circ}$ and $\pm 20^{\circ}$ depict that the coolant coming out of $\mathrm{SH}$ spreads more on to the pressure side surface than the suction side. The contour at $35^{\circ}$ and $50^{\circ}$ on the suction surface shows the coolant flow downstream of the SS1 row and vividly shows that, with increase in blowing ratio, the coolant jet gets lifted off more from the surface and in turn entraps the hot mainstream beneath it, whereas on to the pressure side, at $35^{\circ}$ and $50^{\circ}$, plots depict an improvement in the concentration of coolant with increase in blowing ratio and a denser and thicker cover of coolant is observed. On the contrary, downstream of SS2 and PS2 rows, a better spread and attachment of coolant on to the surface are seen for $M=1$. When the blowing ratio increases, the coolant is slightly getting detached and hot mainstream is seen penetrating the region between the film 


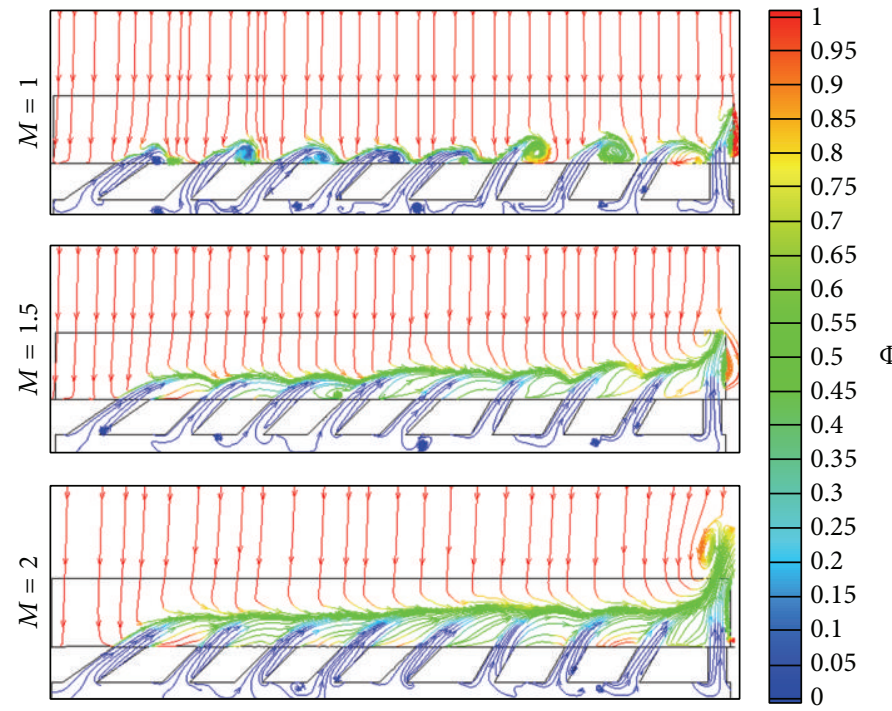

FIGURE 12: Streamlines coloured by nondimensional temperature $(\theta)$ showing coolant-mainstream interaction at the leading edge stagnation region $(\alpha=0)$ for blowing ratios: (a) $M=1$, (b) $M=1.5$, and (c) $M=2$.

holes. Moreover, at higher blowing ratios, the coolant is seen to be gathering near the tip region while a meager amount of coolant is present near the hub. This is mainly due to the high spanwise inclination of showerhead holes near the hub. At higher blowing ratios, the coolant effusing out of these holes attains enough momentum to push the coolant coming out of adjacent holes towards the tip. This phenomenon can be better understood with the aid of Figure 12 which shows the coolant-mainstream interaction at the stagnation region $(\alpha=0)$. It is also observed that, for all rows of holes, the coolant effusing out of the holes closer to the tip region which are less inclined to the spanwise direction shows a higher tendency to liftoff from the surface. The tendency to liftoff also decreases when moved towards the hub region, as the holes gradually get more inclined to the spanwise direction.

4.3. Effect of Blowing Ratio on Effectiveness. The effect of blowing ratio on the overall effectiveness is different for suction and pressure side surface of the leading edge as can be seen from Figure 13. Whilst the effectiveness appears to improve with blowing ratio on the pressure side surface, it is seen to decrease on the suction side surface. The above qualitative explanation can be justified with the spanwise averaged effectiveness plot at various streamwise angles from the stagnation region as shown in Figure 14.

On the pressure side surface, downstream of $\mathrm{SH}$ and PS1 holes, the effectiveness is least for $M=1$ for all three Reynolds numbers. Moreover the effectiveness gradient between two rows of holes is also highest for $M=1$ whereas it is least for $M=2$ especially downstream of $\mathrm{SH}$ row. This is due to the uniform and wide coverage of coolant in that region at $M=2$, as discussed from Figure 11. At $M=1.5$ and $M=2$, the effectiveness curves are almost overlapping downstream of PS1 for all Reynolds numbers. After PS2, on the contrary, effectiveness is seen decreasing with increase in blowing ratio. This is vivid from $\mathrm{Re}_{1}$, whereas, for higher Reynolds numbers, the effectiveness curves in this region are almost overlapping for $M=1$ and 1.5.

On the suction side surface, the effectiveness is least for $M=2$ throughout due to the coolant jet getting lifted off from the surface as explained in the previous section. The effectiveness gradient between two rows of holes is also found highest for $M=2$ case and least for $M=1$. Effectiveness distribution at $M=1$ and $M=1.5$ is almost overlapping downstream of $\mathrm{SH}$ and $\mathrm{SS} 1$ holes for $\mathrm{Re}_{1}$ and $\mathrm{Re}_{3}$ cases. For $\mathrm{Re}_{2}$ case, the effectiveness values are slightly reduced at $M=1.5$ and the distribution moves close to $M=2$. Downstream of SS2, the effectiveness distribution is distinct and the trend is similar for all Reynolds numbers. The effectiveness is decreasing with increasing blowing ratio. The effectiveness distribution at $M=1.5$ is in between that of $M=1$ and $M=2$ at almost throughout the leading edge region and at all Reynolds numbers. Hence, when area weighted average of the whole surface is taken, the overall effectiveness is higher for $M=1.5$. But the gradient in effectiveness between the pressure and suction side is least for $M=1$ case.

The averaged values of effectiveness are found quite high for Material B because the effect of impingement cooling is felt more due to the high conductivity of the material. From the effectiveness contours in Figure 13, it is very clear that the distribution is uniform throughout the leading edge region compared to Material A. Due to lateral conduction within the plate, gradients in the effectiveness between rows of holes are very small. Even though the variation is less, zones of relatively higher effectiveness can be found in the pressure side surface of the leading edge compared to the suction side surface. Further insight into this can be obtained from the plot of spanwise averaged effectiveness from Figure 14.

The effect of blowing ratio, though prevalent, is considerably smaller compared to the low conductivity material. 


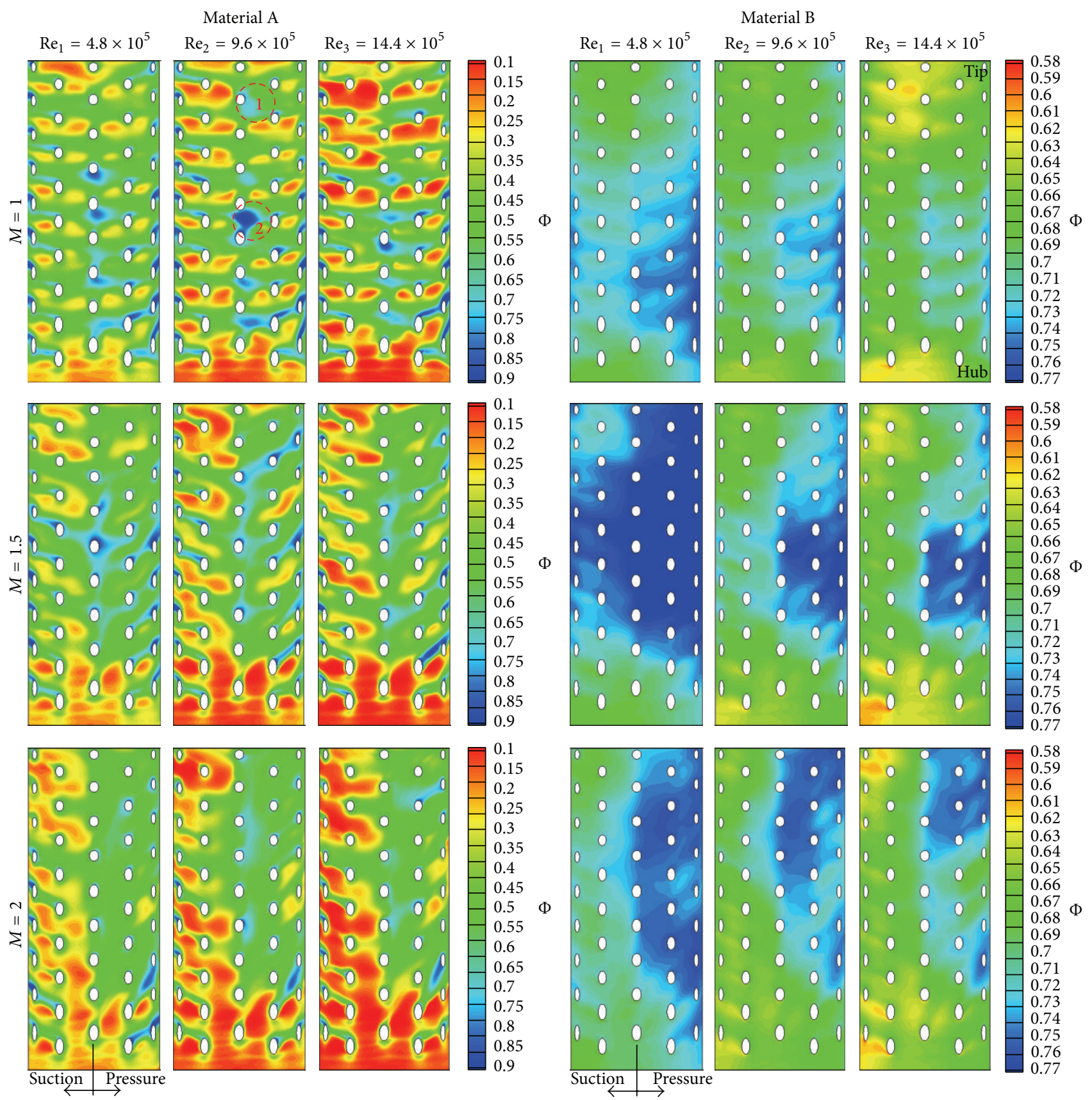

FIgURE 13: Overall effectiveness contours at all three blowing ratios and Reynolds numbers for Materials A and B.

At $M=1.5$, the effectiveness values are relatively high compared to other blowing ratios and this difference is more distinct at $\mathrm{Re}_{1}$. At higher Reynolds numbers this difference in effectiveness values is found to be reduced. On the suction side surface downstream of the $\mathrm{SH}$ row, the effectiveness curves at all blowing ratios are overlapping at $\mathrm{Re}_{2}$ and $\mathrm{Re}_{3}$ and the same is found in the downstream region of SS1 at $\mathrm{Re}_{3}$. Downstream of PS2, the effectiveness is highest at $M=1.5$ at all Reynolds numbers, whereas, downstream of SS2, the highest effectiveness found at $M=1.5$ gradually changes to $M=1$ as the Reynolds number increases. A close observation of the plot reveals that the effectiveness values on the pressure side surface are least at $M=1$ and those on the suction surface are least at $M=2$ at all Reynolds numbers. Hence effectiveness at $M=1.5$ is comparatively more consistent and higher for $M=1.5$. The same scenario was seen for low conductivity material too.

4.4. Effect of Reynolds Number on Effectiveness. For Material A, it can be seen from Figure 15 that effectiveness decreases with increase in Reynolds number for all blowing ratios at all regions of the leading edge except the region between $\mathrm{SH}$ and 
TABLE 1: Area weighted averaged values of effectiveness at interaction and target surface.

\begin{tabular}{ccccc}
\hline & \multicolumn{2}{c}{ Material A } & \multicolumn{2}{c}{ Material B } \\
& $\begin{array}{c}\text { Tnteraction } \\
\text { surface }\end{array}$ & $\begin{array}{c}\text { Target } \\
\text { surface }\end{array}$ & $\begin{array}{c}\text { interaction } \\
\text { surface }\end{array}$ & $\begin{array}{c}\text { Target } \\
\text { surface }\end{array}$ \\
\hline $\mathrm{Re}_{1}$ & 0.475 & 0.923 & 0.719 & 0.737 \\
$\mathrm{Re}_{2}$ & 0.442 & 0.934 & 0.7 & 0.725 \\
$\mathrm{Re}_{3}$ & 0.405 & 0.94 & 0.678 & 0.709 \\
\hline
\end{tabular}
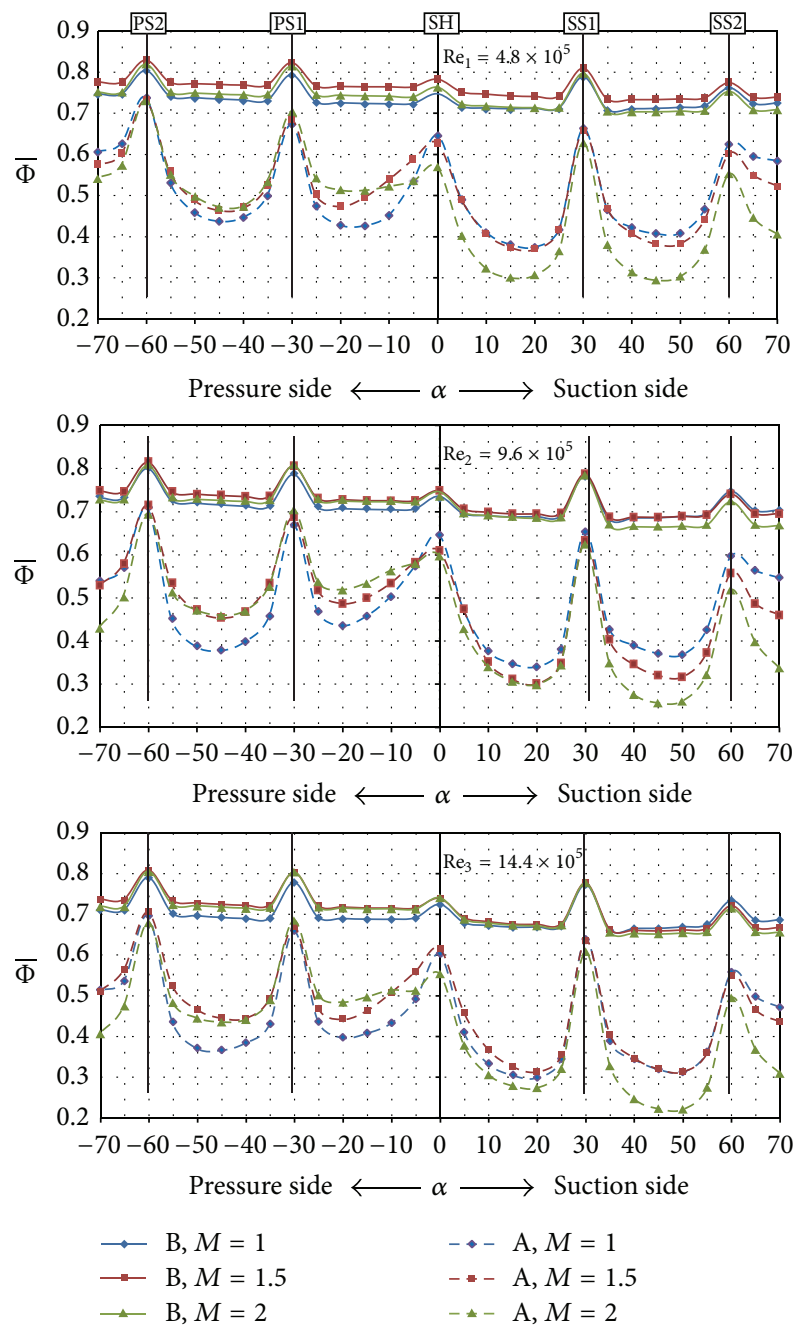

FIGURE 14: Spanwise averaged overall effectiveness at various streamwise angles, $\alpha$.

PS1. In that region the value is higher for effectiveness at $\mathrm{Re}_{2}$ and this is later explained with Figures 16 and 17. For Material $\mathrm{B}$, the effectiveness is decreasing with increase in Reynolds number throughout the leading edge for all blowing ratios.

Table 1 shows the area weighted average of effectiveness at the outer and inner surface of the leading edge. Interaction surface is where the coolant, coming out of the film holes, interacts with the mainstream and target surface is where the coolant impinges. It can be clearly seen that as Reynolds number increases, effectiveness decreases at the interaction
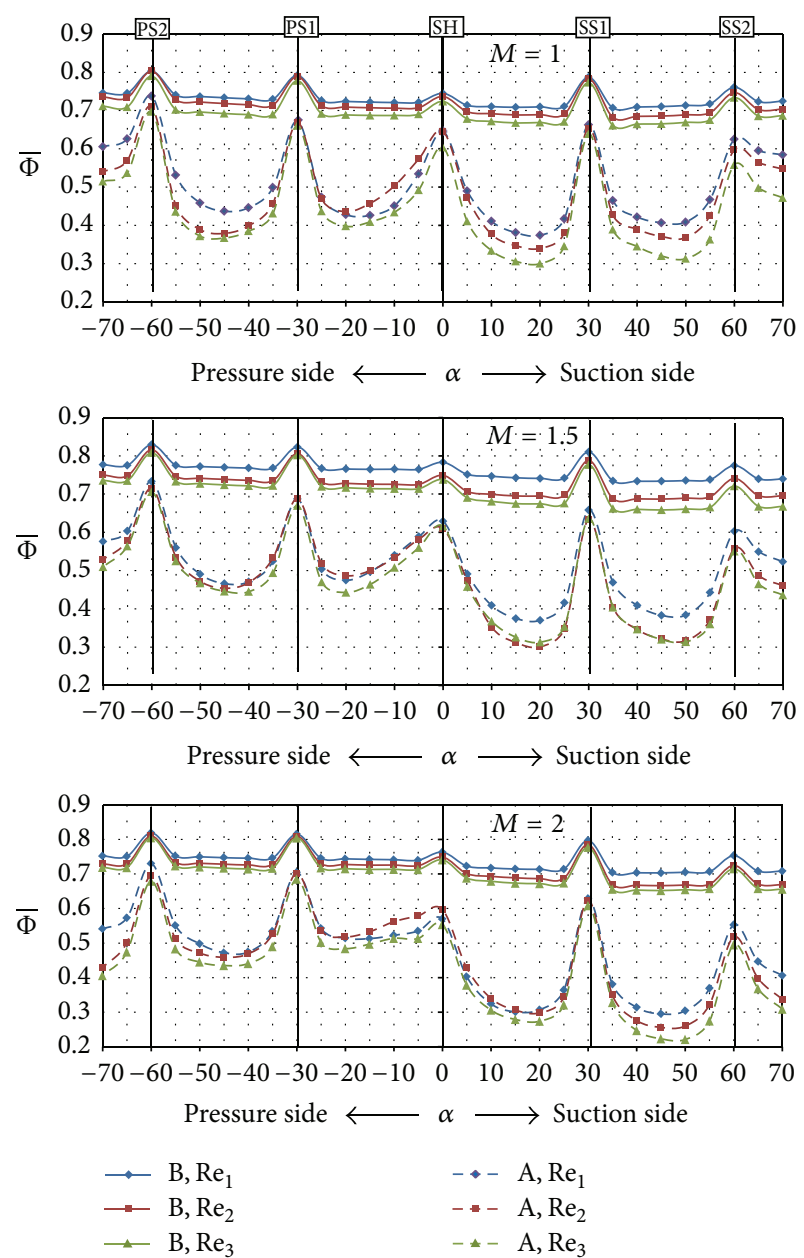

FIGURE 15: Spanwise averaged overall effectiveness at various streamwise angles, $\alpha$.

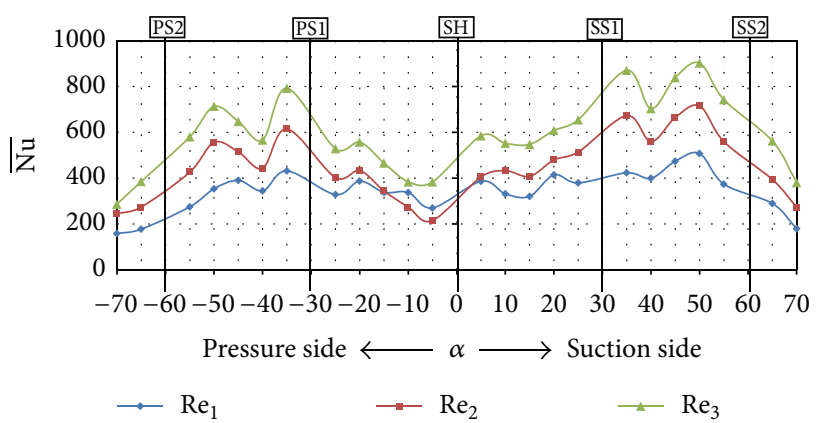

FIGURE 16: Spanwise averaged Nusselt number distribution at $M=1$ for Material A.

surface whereas it increases at the target surface for Material A. This shows that, with increase in Reynolds number, the heat transfer at both interaction and target surfaces increases. The values for Material B however show a decrease in effectiveness at both the interaction and target surfaces with increase in Reynolds number. This shows that even though heat transfer rate increases at both the surfaces, the increase in heat transfer at the interaction surface is more dominant. This 


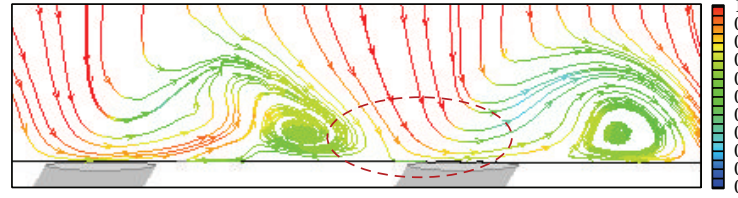

(a)

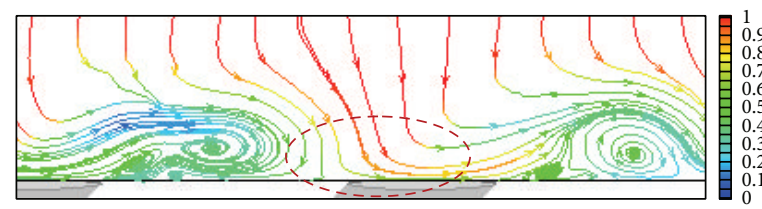

(c)

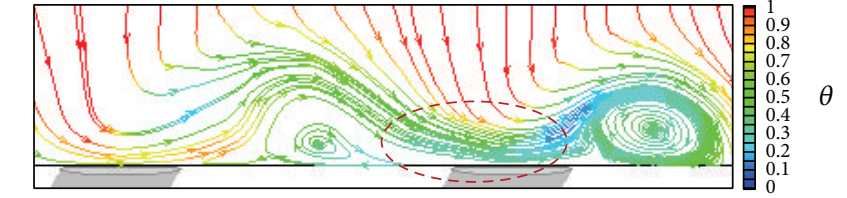

(b)

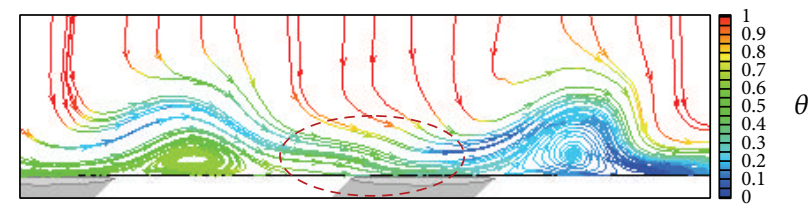

(d)

FIGURE 17: Streamlines coloured by nondimensional temperature at a wall-normal plane $5^{\circ}$ downstream SH.

increase in heat transfer with Reynolds number is evident from the spanwise averaged Nusselt number plot shown in Figure 16.

An overlapping is seen in the graph in the immediate downstream region of $\mathrm{SH}$ row towards the pressure side where the heat transfer is found low for $\mathrm{Re}_{2}$. This is mainly attributed to the cold spots as indicated in Figure 13. Flow behavior in this region is studied for $\mathrm{Re}_{1}$ and $\mathrm{Re}_{2}$ by drawing pathlines (Figure 17) in a plane drawn 5 degrees downstream of $\mathrm{SH}$ row on the pressure side surface. Figures 17 (a) and 17(b) correspond to the location of spot 1 of Figure 13 at $\mathrm{Re}_{1}$ and $\mathrm{Re}_{2}$, respectively. Similarly Figures $17(\mathrm{c})$ and $17(\mathrm{~d})$ correspond to the location of spot 2 on Figure 13 at $\operatorname{Re}_{1}$ and $\mathrm{Re}_{2}$, respectively. It can be seen that the region between the two eddies is occupied by the mainstream in the cases of $\mathrm{Re}_{1}$, whereas, in the cases of $\mathrm{Re}_{2}$, that region is filled by the coolant effusing out of the adjacent hole and hence results in improved effectiveness.

\section{Conclusions}

A computational and experimental study is carried out on the leading edge of a typical gas turbine nozzle guide vane. The effect of blowing ratio and Reynolds number is studied by considering two materials: Material A $(k=0.2 \mathrm{~W} / \mathrm{mK})$ and Material $\mathrm{B}(k=14.9 \mathrm{~W} / \mathrm{mK})$ of low and high thermal conductivity, respectively. The heat transfer and overall effectiveness distributions at the leading edge are extensively studied and reported. These results are explained with the aid of pathlines, nondimensional temperature contours, and Nusselt number distributions describing the mainstreamcoolant interaction at the exit of film holes. The salient conclusions drawn from the study are as follows.

(1) The computational turbine NGV cascade model is validated with the experimental data, as a close agreement in static pressure distribution and overall effectiveness distribution on the vane surface is obtained.

(2) The overall effectiveness value of Material B is higher and its distribution in streamwise and spanwise directions is more uniform compared to Material A owing to the high conductivity of the former. The sudden peaks and valleys appearing in the effectiveness distribution of Material A disappear in the case of Material $\mathrm{B}$ owing to the high lateral diffusion within the plate.

(3) The effect of blowing ratio is different for the pressure side and suction side of the stagnation line. As the blowing ratio increases, the coolant tends to distribute more towards the pressure surface. Hence, with increase in blowing ratio, effectiveness increased on the pressure side and decreased on the suction side. For Material A, the effectiveness is higher on the pressure side at $M=2$ and on the suction side at $M=$ 1 . When considering the whole blade, a more uniform distribution of overall effectiveness between pressure and suction side was noticed at $M=1$, resulting in less thermal gradient whereas the averaged overall effectiveness value is higher at $M=1.5$. For Material $\mathrm{B}$, the overall effectiveness value is higher at $M=1.5$ throughout the leading edge. For both Materials A and $\mathrm{B}$, when blowing ratio was increased from $M=1$ to $M=2$, the region with higher effectiveness was seen getting shifted from hub to tip.

(4) An increase in Reynolds number has showed an increase in heat transfer on both the external and internal sides of the leading edge even though external heat transfer is more dominant. An increase in Reynolds number at a particular blowing ratio results in a decrease in the overall effectiveness throughout the leading edge for Material B. While Material A also exhibits similar behavior at most of the leading edge, a slight disagreement is seen in the region between $\mathrm{SH}$ and PS1 rows where the maximum effectiveness is at $\mathrm{Re}_{2}$ owing to the formation of cold spots.

\section{Nomenclature}

$C_{h}$ : Chord length, $\mathrm{m}$

$C_{p}$ : Coefficient of pressure $\left(p-p_{m}\right) /\left(0.5 * \rho * v_{m}^{2}\right)$

$h$ : Heat transfer coefficient, $Q^{\prime \prime} /\left(T_{\mathrm{aw}}-T_{w}\right), \mathrm{W} / \mathrm{m}^{2}-\mathrm{K}$

$k$ : Thermal conductivity $(\mathrm{W} / \mathrm{m}-\mathrm{K})$

$x$ : Streamwise direction, $\mathrm{m}$ 
$M: \quad$ Blowing ratio $\left(\rho_{c} v_{c} / \rho_{m} v_{m}\right)$

$\mathrm{Nu}$ : Nusselt number, $h C_{h} / k$

$\overline{\mathrm{Nu}}$ : Spanwise averaged $\mathrm{Nu}$

$p$ : Static pressure

$Q^{\prime \prime}$ : Total surface heat flux, $W / \mathrm{m}^{2}$

Re: Reynolds number $\left(\rho v_{e} C_{h} / \mu\right)$

T: $\quad$ Temperature (K)

$v$ : Velocity magnitude

SST: Shear stress transport.

\section{Greek}

$\theta$ : Nondimensional temperature $\left(T-T_{c}\right) /\left(T_{m}-T_{c}\right)$

$\eta$ : Adiabatic effectiveness $\left(T_{m}-T_{\mathrm{aw}}\right) /\left(T_{m}-T_{c}\right)$

$\Phi$ : Overall cooling effectiveness $\left(T_{m}-T_{w}\right) /\left(T_{m}-T_{c}\right)$

$\bar{\Phi}$ : Spanwise averaged $\Phi$

$\alpha$ : Streamwise angle with respect to stagnation line (o)

$\rho$ : Fluid density

$\kappa$ : Turbulent kinetic energy, $\mathrm{m}^{2} / \mathrm{s}^{2}$

$\omega$ : Specific dissipation rate, $1 / \mathrm{sec}$

$\mu$ : Coefficient of viscosity, Ns $/ \mathrm{m}^{2}$.

\section{Subscript}

aw: Adiabatic wall

amb: Ambient

$c$ : Coolant

$e$ : Exit of cascade

$f: \quad$ Fluid

$m$ : Mainstream

min: Minimum

$s: \quad$ Solid

$w$ : Wall.

\section{Conflict of Interests}

The authors declare that there is no conflict of interests regarding the publication of this paper.

\section{Acknowledgment}

The authors are grateful to Gas Turbine Research Establishment (GTRE), Bangalore, for supporting this project through GATET program.

\section{References}

[1] A. B. Mehendale and H. Je-Chin, "Reynolds number effect on leading edge film effectiveness and heat transfer coefficient," International Journal of Heat and Mass Transfer, vol. 36, no. 15, pp. 3723-3730, 1993.

[2] S. Ou and R. Rivir, " $90^{\circ}$ skew leading edge film cooling effectiveness, heat transfer, and discharge coefficients for cylindrical film holes at high free stream turbulence," in Proceedings of the RTO AVT Symposium on "Advanced Flow Management: Part A-Vortex Flows and High Angle of Attack for Military Vehicles, RTO-MP-069(I), Loen, Norway, May 2001.

[3] S. Ou and R. B. Rivir, "Leading edge film cooling heat transfer with high free stream turbulence using a transient liquid crystal image method," International Journal of Heat and Fluid Flow, vol. 22, no. 6, pp. 614-623, 2001.

[4] K. Funazaki, H. Kawabata, D. Takahashi, and Y. Okita, "Experimental and numerical studies on leading edge film cooling performance: effects of hole exit shape and freestream turbulence," in Proceedings of ASME Turbine Technical Conference and Exposition, GT2012-68217, Copenhagen, Denmark, 2012.

[5] H. Reiss and A. Bölcs, "Experimental study of showerhead cooling on a cylinder comparing several configurations using cylindrical and shaped holes," Journal of Turbomachinery, vol. 122, no. 1, pp. 161-169, 2000.

[6] W. D. York and J. H. Leylek, "Leading-edge film-colling physics. Part III. Diffused hole effectiveness," ASME Journal of Turbomachinery, vol. 125, no. 2, pp. 252-259, 2003.

[7] Y. Lu, D. Allison, and S. V. Ekkad, "Turbine blade showerhead film cooling: Influence of hole angle and shaping," International Journal of Heat and Fluid Flow, vol. 28, no. 5, pp. 922-931, 2007.

[8] A. Kassab, E. Divo, J. Heidmann, E. Steinthorsson, and F. Rodriguez, "BEM/FVM conjugate heat transfer analysis of a three-dimensional film cooled turbine blade," International Journal of Numerical Methods for Heat and Fluid Flow, vol. 13, no. 5-6, pp. 581-610, 2003.

[9] L. Zhao and T. Wang, "An investigation of treating adiabatic wall temperature as the driving temperature in film cooling studies," ASME Journal of Turbomachinery, vol. 134, Article ID 061032, pp. 1-9, 2012.

[10] F. Montomoli, M. Massini, H. Yang, and J. C. Han, "The benefit of high-conductivity materials in film cooled turbine nozzles," International Journal of Heat and Fluid Flow, vol. 34, pp. 107-116, 2012.

[11] N. Moritz, K. Kusterer, D. Bohn, T. Sugimoto, R. Tanaka, and T. Taniguchi, "Conjugate calculation of a film-cooled blade for improvement of the leading edge cooling configuration," Propulsion and Power Research, vol. 2, pp. 1-9, 2013.

[12] M. L. Nathan, T. E. Dyson, D. G. Bogard, and S. D. Bradshaw, "Adiabatic and overall effectiveness for the showerhead film cooling of a turbine vane," in Proceedings of the ASME Turbo Expo: Turbine Technical Conference and Exposition (GT '12), pp. 1537-1547, Copenhagen, Denmark, June 2012.

[13] R. K. Panda and B. V. S. S. S. Prasad, "Conjugate heat transfer from a flat plate with combined impingement and film cooling," in Proceedings of the ASME Turbo Expo: Turbine Technical Conference and Exposition (GT '12), pp. 347-356, Copenhagen, Denmark, June 2012.

[14] M. Vollmer and K. P. Mollmann, Infrared Thermal Imaging: Fundamentals, Research and Applications, Wiley-VCH, 2010. 

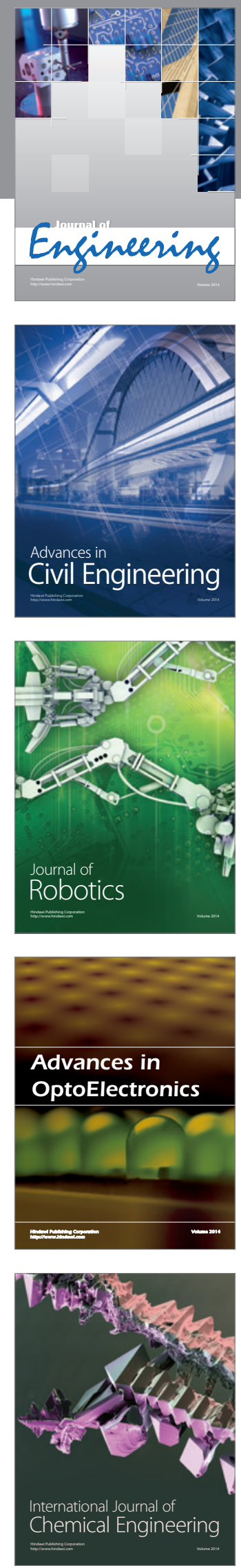

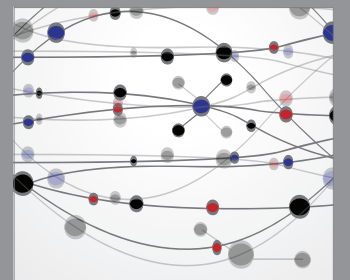

The Scientific World Journal
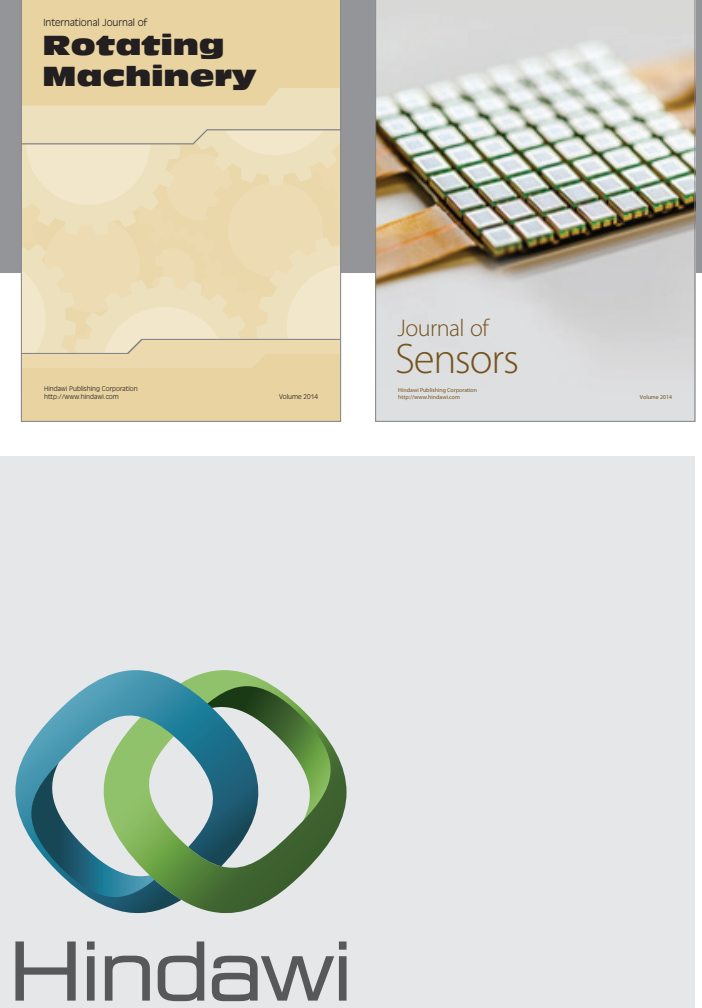

Submit your manuscripts at http://www.hindawi.com
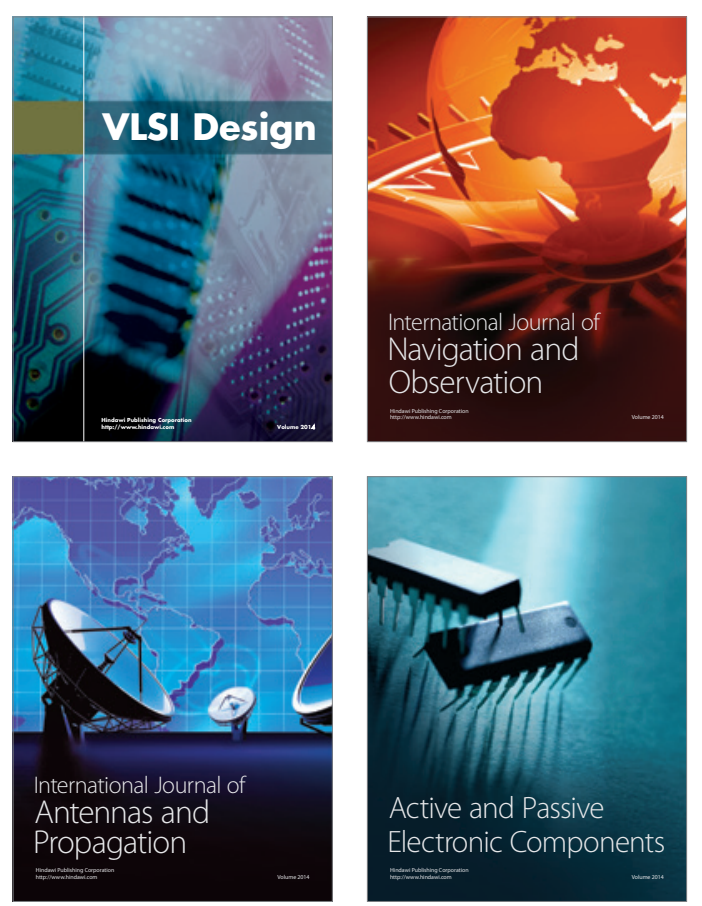
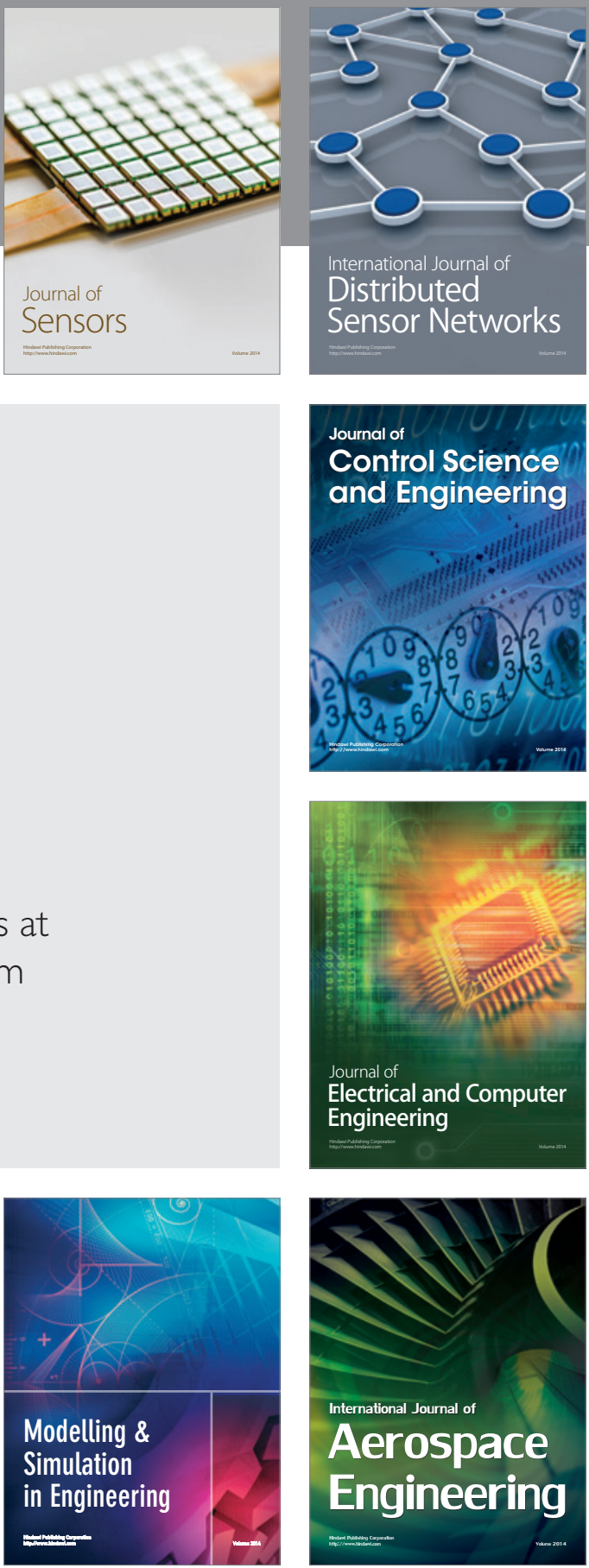

Journal of

Control Science

and Engineering
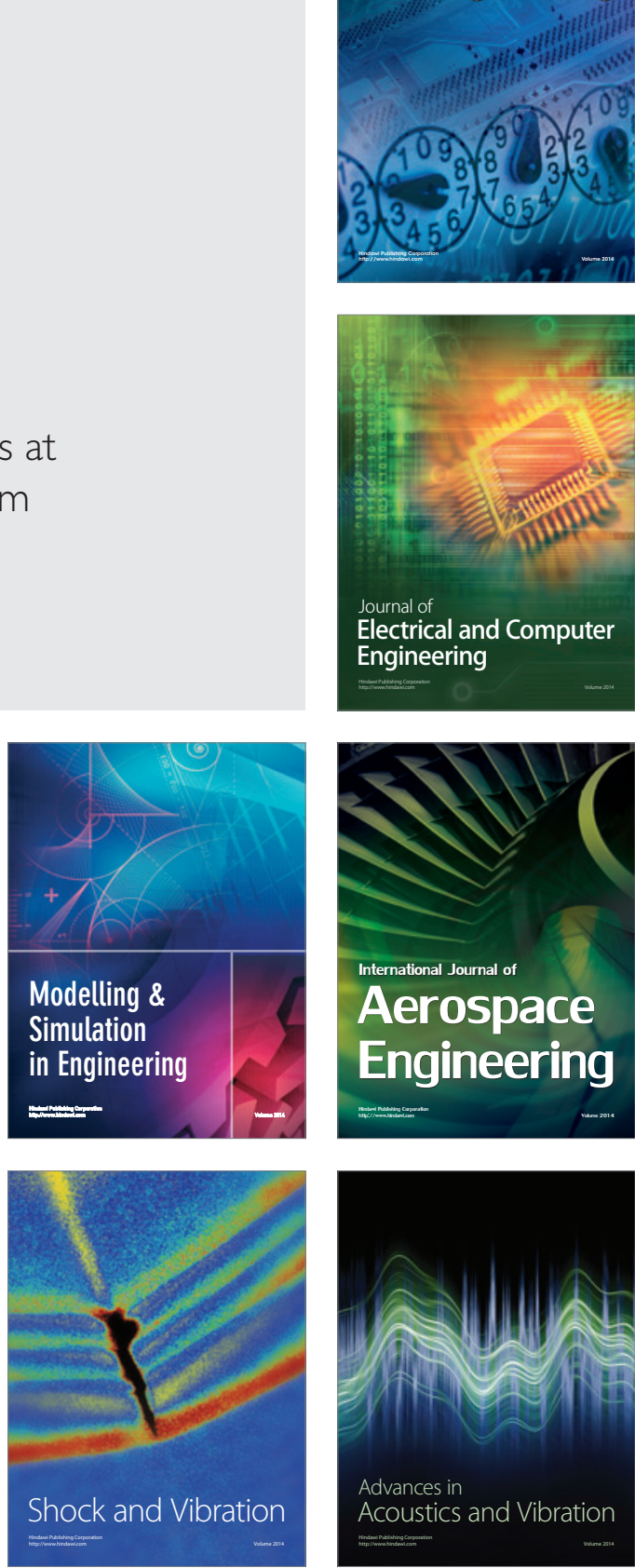